\title{
PENGARUH PERBANDINGAN TERIGU DAN PASTA BROKOLI (Brassica oleraceae L.) TERHADAP KARAKTERISTIK DONAT
}

\author{
The Effects of Wheat Flour and Broccoli Paste (Brassica oleraceae L.) Ratio on \\ The Characteristic of Donut
}

\author{
Adryan Adhitama Shahrirputra ${ }^{1)}$, Putu Timur Ina ${ }^{2)}$, I Ketut Suter ${ }^{2)}$ \\ ${ }^{1)}$ Mahasiswa Program Studi Ilmu dan Teknologi Pangan, Fakultas Teknologi Pertanian, \\ Universitas Udayana \\ ${ }^{2)}$ Dosen Program Studi Ilmu dan Teknologi Pangan, Fakultas Teknologi Pertanian, \\ Universitas Udayana \\ Kampus Bukit Jimbaran, Badung-Bali
}

\begin{abstract}
This research was conducted with the aims to determine the effect of wheat flour and broccoli paste to the characteristics of donut and obtain a ratio of wheat flour and broccoli paste which able to produce donut with the best characteristics. This research used randomized block design with the treatment of wheat flour and broccoli paste ratio 100\%:0\%; 90\%:10\%; 80\%:20\%; 70\%:30\%; 60\%:40\%. The treatment was repeated 3 times to obtain 15 units of experiment. The data were then analyzed by Analysis of Variance and if the treatment had an significant effect, the Duncan test were performed. The results showed that the ratio of wheat and broccoli paste had an significant effect on water content, fat content, crude fiber content, vitamin C content, chlorophyll content, swelling ability, flavor (hedonic), texture (scoring) of donut. Ratio of 60\% wheat : $40 \%$ broccoli paste is the best donut characteristic with $18.80 \%$ water content, $17.30 \%$ fat content, $4.92 \%$ crude fiber content, $2.93 \mathrm{mg} / \mathrm{g}$ vitamin C content, $3.97 \mathrm{mg} / \mathrm{kg}$ chlorophyll content, $27.20 \%$ swelling ability, rather liked color, ordinary flavor, soft and rather liked texture, rather liked taste, and overall acceptance is rather liked.
\end{abstract}

Keywords : wheat flour, broccoli paste, donut

\section{PENDAHULUAN}

Donat adalah produk pangan olahan berbentuk bulat dengan lubang di bagian tengahnya yang merupakan hasil proses penggorengan adonan yang telah difermentasi (Anon., 1981). Donat biasanya dibuat dari adonan terigu, ragi, gula, telur dan mentega yang memiliki variasi rasa yang dihasilkan dengan taburan gula halus, coklat cair, coklat butir diatasnya. Karena itu donat tidak hanya disukai oleh kalangan dewasa tapi juga sangat disukai dikalangan anak - anak. Donat merupakan salah satu makanan populer masyarakat dunia, bahkan saat ini di Amerika lebih dari 10 juta donat diproduksi setiap tahun
(Zuhrina, 2011). Di Indonesia donat sudah menjadi salah satu makanan favorit dan banyak dijajakan, baik di mal-mal maupun pinggir jalan. Sampai sekarang, masih banyak penjaja donat baru bermunculan mulai dari yang independen hingga yang ikut kemitraan atau waralaba dari merek-merek tertentu (Junda 2013).

Kebanyakan anak-anak tidak suka ataupun jarang mengkonsumsi sayur. Salah satu upaya untuk meningkatkan minat anak-anak untuk menkonsumsi sayur adalah dengan memanfaatkan sayur sebagai bahan dasar pembuatan donat. Sayur yang dapat ditambahkan dalam pembuatan donat, salah satunya

*Korespondensi Penulis:

E-mail: mystogankarasu@gmail.com ${ }^{1)}$ 
adalah brokoli, disamping itu kelemahan donat yang dibuat dari terigu memiliki nilai gizi yang kurang seperti serat dan vitamin sehingga penambahan pasta brokoli diharapkan dapat meningkatkan nilai gizi donat.

Brokoli (Brassica oleracea L.) adalah tanaman sayuran yang termasuk dalam suku kubis - kubisan atau Brassicaceae, yang banyak terdapat dipasaran sehingga cukup mudah untuk didapatkan. Nilai gizi brokoli seperti vitamin A, B, C, kalsium, zat besi, dan asam folat yang baik untuk kesehatan tubuh, serta mengandung senyawa antikanker sulforaphane sehingga dapat mengurangi resiko terkena kanker (Wasonowati, 2009). Penelitian di Amerika menemukan bahwa brokoli mengandung kalsium pektat yang mampu mengikat asam empedu, sehingga lebih banyak kolesterol yang tertahan dihati dan sedikit kolesterol yang dilepaskan ke aliran darah. Efektifitas sayuran ini dalam menurunkan kadar kolesterol sama dengan obat kolesterol. (Yenti, 2016). Selain itu, brokoli juga mengandung klorofil sebagai antioksidan serta sumber serat dan berbagai mineral penting yang dapat dijadikan sebagai salah satu cara untuk mempertahankan sistem kekebalan tubuh manusia dan mempercepat penyembuhan penyakit (Aminah, 2016).

Pengolahan brokoli menjadi makanan masih sangat jarang selain diolah menjadi sayur. Disamping itu konsumsi sayuran kurang diminati oleh sebagian masyarakat terutama anak - anak. Penambahan pasta brokoli pada donat diharapkan dapat meningkatkan nilai gizi dan komponen bioaktif dari donat sebagai pangan fungsional dan penganekaragaman pangan serta dapat meningkatkan jumlah konsumsi sayuran dikalangan masyarakat terutama anak - anak.

\section{METODE PENELITIAN}

\section{Tempat dan Waktu Penelitian}

Penelitian ini dilaksanakan di Laboratorium Analisis Pangan, Laboratorium Pengolahan Pangan, serta Laboratorium Rekayasa Proses dan Pengendalian Mutu Fakultas Teknologi Pertanian Universitas Udayana. Pelaksanaan penelitian ini dilakukan mulai bulan September sampai dengan bulan Desember 2018.

\section{Bahan dan Alat}

Bahan-bahan yang digunakan dalam melaksanakan penelitian ini terdiri dari bahan baku, bahan tambahan, dan bahan kimia. Bahan baku terdiri dari brokoli yang diperoleh di pasar Pemogan dan terigu merek cakra kembar yang diperoleh dari toko Fenny, sedangkan bahan tambahan terdiri dari telur, baking powder, ragi, minyak goreng dan margarin merek forvita yang diperoleh di toko Fenny. Bahan kimia yang digunakan dalam melakukan analisis meliputi aquades, $\mathrm{H} 2 \mathrm{SO} 4, \mathrm{NaOH}$, Heksan, K2SO4, aseton, alkohol 95\%, Sodium Fosfat, Amonium Molibdat, Asam Askorbat.

Alat - alat yang digunakan untuk membuat donat adalah meja, kompor gas (Rinnai), pisau, loyang, cetakan donat, waskom, kain basah, roolpan, blender (Phlips), timbangan digital (ACIS), wajan penggorengan, dan sendok. Alat yang digunakan untuk analisis sifat fisik dan kimia adalah penggaris, lumpang, desikator, cawan porselin, oven (Memmert), timbangan analitik (Shimadzu), 
pinset, erlenmeyer (Pyrex), gelas beaker (Pyrex), gelas ukur (Pyrex), alumunium foil (Klin Pak), pipet mikro (Socorex), pipet volume (Pyrex), pompa karet, tip, labu takar (Pyrex), labu lemak (Pyrex), soxhlet, kertas whatman no 42, kertas saring, corong, tabung reaksi (Pyrex), vortex (Maxi Mix II Type 367000), waterbath (thermology), dan spektrofotometer (Thermo Scientific Genesys 10S UV-Vis).

\section{Pelaksanaan Penelitian}

Rancangan Penelitian dan Analisis Data

Rancangan yang digunakan pada penelitian ini adalah Rancangan Acak Kelompok (RAK) dengan perlakuan perbandingan terigu dan pasta brokoli yang digunakan pada pembuatan donat, yaitu : $\mathrm{P} 0=100 \%$ terigu : $0 \%$ pasta brokoli, $\mathrm{P} 1=90 \%$ terigu : $10 \%$ pasta brokoli, $\mathrm{P} 2=80 \%$ terigu : $20 \%$ pasta brokoli, $\mathrm{P} 3=70 \%$ terigu : $30 \%$ pasta brokoli, $\mathrm{P} 4=60 \%$ terigu : $40 \%$ pasta brokoli.

Masing-masing perlakuan diulang sebanyak 3 kali sehingga diperoleh 15 unit percobaan. Data yang diperoleh dianalisis dengan sidik ragam dan apabila perlakuan berpengaruh nyata terhadap variabel yang diamati maka dilanjutkan dengan uji Duncan (Gomez dan Gomez, 1995)

\section{Pembuatan Pasta Brokoli}

Brokoli segar dipisahkan dari batang kemudian disortasi dan dicuci dengan air bersih, setelah itu diblansing dengan uap panas (dikukus) pada suhu $60^{\circ} \mathrm{C}$ selama 3 menit. Brokoli yang telah diblansing kemudian dihaluskan dengan blender sehingga diperoleh pasta brokoli.

\section{Pembuatan donat}

Formulasi donat per 100 gram campuran terigu dan pasta brokoli disajikan pada Tabel 1 .

Tabel 1. Formula Donat

\begin{tabular}{clccccc}
\hline No Komposisi & \multicolumn{5}{c}{ Perlakuan } \\
\cline { 3 - 6 } & & P0 & P1 & P2 & P3 & P4 \\
\hline 1 & Terigu (\%) & 100 & 90 & 80 & 70 & 60 \\
2 & Pasta brokoli (\%) & 0 & 10 & 20 & 30 & 40 \\
3 & Kuning telur (\%) & 20 & 20 & 20 & 20 & 20 \\
4 & Gula pasir (\%) & 10 & 10 & 10 & 10 & 10 \\
5 & Margarin (\%) & 20 & 20 & 20 & 20 & 20 \\
6 & Baking powder (\%) & 1 & 1 & 1 & 1 & 1 \\
7 & Ragi (\%) & 1 & 1 & 1 & 1 & 1 \\
\hline
\end{tabular}

Keterangan : Persentase diatas dihitung berdasarkan jumlah terigu dan pasta brokoli

Bahan baku dan bahan tambahan dipersiapkan kemudian dilakukan penimbangan sesuai formula. Gula dan margarin dicampur dengan mixer selama 2 menit kemudian dimasukkan kuning telur dan dicampur dengan mixer selama 2 menit setelah itu dimasukan terigu dan pasta brokoli sesuai perlakuan, baking powder, ragi dan diuleni sampai adonan menjadi kalis. Setelah kalis adonan ditimbang sebanyak 35 gram. Adonan dibentuk bulat dan didiamkan selama 10 menit dengan ditutup dengan kain basah. Adonan kemudian digiling menggunakan roolpan. Adonan kemudian dicetak menggunakan cetakan donat. Adonan yang telah dicetak diletakan pada loyang dan difermentasi selama 1 jam dengan ditutup kain basah. Selanjutnya, adonan digoreng 
menggunakan minyak goreng pada suhu $190^{\circ} \mathrm{C}$ selama 2 menit.

\section{Variabel yang Diamati}

Variabel yang diamati dalam penelitian ini adalah kadar air, kadar lemak, kadar serat kasar (Sudarmadji et al., 1997), kadar vitamin C (Vuong, et al., 2014), kadar klorofil (Nollet, 2004), daya kembang serta sifat sensoris meliputi warna, aroma, rasa (uji hedonik), tekstur (uji hedonik dan uji skoring) dan penerimaan keseluruhan (uji hedonik) (Soekarto, 1985).

\section{HASIL DAN PEMBAHASAN}

Hasil analisis rata-rata kadar air, kadar lemak, kadar serat kasar, kadar vitamin $\mathrm{C}$, dan kadar klorofil dari terigu dan pasta brokoli dapat dilihat pada Tabel 2. Nilai rata - rata kadar air, kadar lemak, dan kadar serat kasar dari donat yang terbuat dari terigu dan pasta brokoli terdapat pada Tabel 3. Nilai rata - rata kadar vitamin $\mathrm{C}$, kadar klorofil dan daya kembang dari donat yang terbuat dari terigu dan pasta brokoli terdapat pada Tabel 4.

Tabel 2. Nilai Rata-rata Kadar Air, Kadar Lemak, Kadar Serat Kasar, Kadar Vitamin C, dan Kadar Klorofil dari Terigu dan Pasta Brokoli.

\begin{tabular}{lcc}
\hline \multicolumn{1}{c}{ Komponen } & Terigu & Pasta Brokoli \\
\hline Kadar Air $(\%)$ & $12,18 \pm 0,05$ & $87,86 \pm 0,89$ \\
Kadar Lemak $(\%)$ & $3,30 \pm 0,06$ & $0,26 \pm 0,10$ \\
Kadar Serat Kasar $(\%)$ & $0,45 \pm 0,02$ & $10,05 \pm 0,32$ \\
Kadar Vitamin C $(\mathrm{mg} / \mathrm{g})$ & 0 & $0,69 \pm 0,01$ \\
Kadar Klorofil $(\mathrm{mg} / \mathrm{kg})$ & 0 & $19,94 \pm 5,78$ \\
\hline
\end{tabular}

Tabel 3. Nilai Rata-Rata Kadar Air, Kadar Lemak, Kadar Serat Kasar dari Donat.

\begin{tabular}{cccc}
\hline $\begin{array}{c}\text { Terigu : } \\
\text { Pasta } \\
\text { Brokoli }\end{array}$ & $\begin{array}{l}\text { Kadar } \\
\text { Air }(\%)\end{array}$ & Kadar Lemak $(\%)$ & Kadar Serat Kasar $(\%)$ \\
\hline P0(100:0) & $13,90 \pm 0,89 \mathrm{c}$ & $24,48 \pm 0,89 \mathrm{a}$ & $0,77 \pm 0,08 \mathrm{e}$ \\
P1(90:10) & $15,71 \pm 0,55 \mathrm{~b}$ & $22,46 \pm 0,99 \mathrm{~b}$ & $2,66 \pm 0,09 \mathrm{~d}$ \\
P2(80:20) & $16,35 \pm 0,85 \mathrm{~b}$ & $20,70 \pm 0,97 \mathrm{c}$ & $3,44 \pm 0,21 \mathrm{c}$ \\
P3(70:30) & $17,70 \pm 0,57 \mathrm{a}$ & $18,95 \pm 0,63 \mathrm{~d}$ & $3,72 \pm 0,07 \mathrm{~b}$ \\
P4(60:40) & $18,80 \pm 0,91 \mathrm{a}$ & $17,30 \pm 0,76 \mathrm{e}$ & $4,92 \pm 0,12 \mathrm{a}$ \\
\hline
\end{tabular}

Keterangan: Huruf yang sama dibelakang nilai rata-rata pada kolom yang sama menunjukkan berbeda tidak nyata $(\mathrm{P}>0,05)$.

Tabel 4. Nilai Rata-Rata Kadar Vitamin C, Kadar Klorofil, dan Daya Kembang dari Donat.

\begin{tabular}{cccc}
\hline $\begin{array}{c}\text { Terigu : } \\
\text { Pasta }\end{array}$ & $\begin{array}{c}\text { Kadar Vitamin C } \\
(\mathrm{mg} / \mathrm{g})\end{array}$ & Kadar Klorofil $(\mathrm{mg} / \mathrm{kg})$ & Daya Kembang $(\%)$ \\
Brokoli & $0,00 \mathrm{e}$ & $0,00 \mathrm{c}$ & $32,65 \pm 0,67 \mathrm{a}$ \\
\hline P0(100:0) & $2,46 \pm 0,04 \mathrm{~d}$ & $1,56 \pm 0,32 \mathrm{~b}$ & $31,04 \pm 0,37 \mathrm{~b}$ \\
P1(90:10) & $2,63 \pm 0,11 \mathrm{c}$ & $2,00 \pm 0,42 \mathrm{~b}$ & $30,13 \pm 0,83 \mathrm{~b}$ \\
P2(80:20) & $2,74 \pm 0,05 \mathrm{~b}$ & $2,52 \pm 0,19 \mathrm{~b}$ & $29,61 \pm 0,34 \mathrm{~b}$ \\
P3(70:30) & $2,93 \pm 0,09 \mathrm{a}$ & $3,97 \pm 0,89 \mathrm{a}$ & $27,20 \pm 0,97 \mathrm{c}$ \\
P4(60:40) & &
\end{tabular}

Keterangan: Huruf yang sama dibelakang nilai rata-rata pada kolom yang sama menunjukkan berbeda tidak nyata $(\mathrm{P}>0,05)$. 


\section{Kadar Air}

Hasil sidik ragam menunjukkan bahwa perbandingan terigu dengan pasta brokoli berpengaruh nyata $(\mathrm{P}<0,05)$ terhadap kadar air donat. Tabel 3 menunjukkan nilai rata-rata kadar air donat tertinggi diperoleh dari perlakuan P4 (60\% terigu : 40\% pasta brokoli) yaitu $18,80 \%$ serta berbeda tidak nyata dengan perlakuan P3 (70\% terigu : 30\% pasta brokoli) yaitu $17,70 \%$, sedangkan kadar air donat terendah diperoleh dari perlakuan P0 (100\% terigu : $0 \%$ pasta brokoli) yaitu 13,90\%. Hal ini menunjukkan bahwa semakin banyak penambahan pasta brokoli, maka kadar air donat semakin meningkat. Hal ini disebabkan kadar air pada pasta brokoli lebih tinggi dibandingkan dengan kadar air terigu. Pada Tabel 2 kadar air pasta brokoli sebesar $87,86 \%$ sedangkan kadar air terigu sebesar $12,18 \%$.

\section{Kadar Lemak}

Hasil sidik ragam pada menunjukkan bahwa perbandingan terigu dengan pasta brokoli berpengaruh nyata $(\mathrm{P}<0,05)$ terhadap kadar lemak donat. Tabel 3 menunjukkan nilai rata-rata kadar lemak donat terendah diperoleh dari perlakuan P4 $(60 \%$ terigu : $40 \%$ pasta brokoli) yaitu $17,30 \%$ sedangkan kadar lemak donat tertinggi diperoleh dari perlakuan $\mathrm{P} 0$ (100\% terigu : $0 \%$ pasta brokoli) yaitu $24,48 \%$. Hal ini menunjukkan bahwa semakin tinggi penambahan pasta brokoli, maka kadar lemak donat semakin menurun. Penurunan nilai kadar lemak tersebut sesuai dengan hasil analisis bahan baku terigu dan pasta brokoli pada Tabel 2 yaitu didapatkan kadar lemak terigu 3,30\% sedangkan kadar lemak pasta brokoli $0,26 \%$.

\section{Kadar Serat Kasar}

Hasil sidik ragam pada menunjukkan bahwa perbandingan terigu dengan pasta brokoli berpengaruh nyata $(\mathrm{P}<0,05)$ terhadap kadar serat donat. Tabel 3 menunjukkan kadar serat kasar donat yang dihasilkan berkisar antara $0,77 \%$ sampai dengan $4,92 \%$. Kasar serat kasar donat terendah diperoleh pada perlakuan P0 (100\% terigu : 0\% pasta brokoli) yaitu $0,77 \%$ sedangkan kadar serat kasar donat tertinggi diperoleh dari perlakuan P4 (60\% terigu: $40 \%$ pasta brokoli) yaitu 4,92\%. Pembuatan donat dengan penambahan pasta brokoli yang semakin meningkat mengkasilkan donat dengan kadar serat kasar yang semakin tinggi. Hal ini disebabkan karena kadar serat kasar pasta brokoli lebih tinggi dibandingkan terigu. Peningkatan nilai kadar serat kasar tersebut sesuai dengan hasil analisis bahan baku terigu dan brokoli pada Tabel 2 yaitu didapatkan kadar serat terigu $0,45 \%$ sedangkan kadar serat pasta brokoli $10,05 \%$.

\section{Kadar vitamin C}

Hasil sidik ragam menunjukkan bahwa perbandingan terigu dan pasta brokoli berpengaruh nyata $(\mathrm{P}<0,05)$ terhadap kadar vitamin $\mathrm{C}$ donat. Tabel 4 menunjukkan bahwa kadar vitamin $\mathrm{C}$ pada donat berkisar 0 $\mathrm{mg} / \mathrm{g}$ sampai dengan 2,93 $\mathrm{mg} / \mathrm{g}$. Kadar vitamin $\mathrm{C}$ donat tertinggi diperoleh dari donat pada perlakuan P4 (60\% terigu : $40 \%$ pasta brokoli) yaitu sebesar 2,93 $\mathrm{mg} / \mathrm{g}$, sedangkan kadar vitamin $\mathrm{C}$ donat terendah diperoleh dari donat pada perlakuan P0 (100\% terigu : 0\% pasta brokoli) yaitu $0 \mathrm{mg} / \mathrm{g}$.

Pembuatan donat dengan penambahan pasta brokoli yang semakin meningkat akan 
menghasilkan donat dengan vitamin $C$ yang semakin tinggi. Hal ini disebabkan kadar vitamin $\mathrm{C}$ yang terdapat pada pasta brokoli yaitu sebesar $0,69 \mathrm{mg} / \mathrm{g}$ berdasarkan hasil analisis bahan baku pada Tabel 2, sedangkan kadar vitamin $\mathrm{C}$ pada terigu yaitu $0 \mathrm{mg} / \mathrm{g}$. Semakin tinggi konsentrasi pasta brokoli menyebabkan kadar vitamin $\mathrm{C}$ pada donat meningkat.

\section{Kadar Klorofil}

Hasil sidik ragam menunjukkan perbandingan terigu dan pasta brokoli berpengaruh nyata $(\mathrm{P}<0,05)$ terhadap total klorofil donat. Tabel 4 menunjukan bahwa total klorofil berkisar $0 \mathrm{mg} / \mathrm{kg}$ sampai dengan 3,97 $\mathrm{mg} / \mathrm{kg}$. Total klorofil donat tertinggi diperoleh dari donat pada perlakuan P4 (60\% terigu : $40 \%$ pasta brokoli) yaitu sebesar $3,97 \mathrm{mg} / \mathrm{kg}$, sedangkan total klorofil donat terendah diperoleh dari donat pada perlakuan P0 (100\% terigu : 0\% pasta brokoli) yaitu $0 \mathrm{mg} / \mathrm{kg}$.

Pembuatan donat dengan penambahan pasta brokoli yang semakin meningkat menghasilkan donat dengan total klorofil yang semakin tinggi. Hal ini disebabkan total klorofil pasta brokoli lebih tinggi dibandingkan total klorofil terigu. Berdasarkan analisis bahan baku (Tabel 2) total klorofil pasta brokoli adalah 19,94 $\mathrm{mg} / \mathrm{kg}$, sedangkan total klorofil terigu adalah $0 \mathrm{mg} / \mathrm{kg}$.

\section{Daya Kembang}

Hasil sidik ragam menunjukkan perbandingan terigu dan pasta brokoli berpengaruh nyata $(\mathrm{P}<0,05)$ terhadap daya kembang donat. Tabel 4 menunjukan bahwa daya kembang berkisar 27,20\% sampai dengan $32,65 \%$. Daya kembang donat tertinggi diperoleh dari donat pada perlakuan P0 (100\% terigu : 0\% pasta brokoli) yaitu sebesar $32,65 \%$, sedangkan daya kembang donat terendah diperoleh dari donat pada perlakuan P4 (60\% terigu : $40 \%$ pasta brokoli) yaitu $27,20 \%$.

Pembuatan donat dengan penambahan pasta brokoli yang semakin meningkat menghasilkan donat dengan daya kembang yang semakin rendah. Hal ini dikarenakan semakin besar penambahan pasta brokoli terhadap terigu maka semakin berkurang kandungan gluten pada adonan donat. Gluten yang berasal dari terigu mempunyai sifat membuat adonan menjadi kuat dan elastis. Gluten berperan saat gas $\mathrm{CO} 2$ yang dihasilkan pada proses fermentasi terperangkap dalam adonan donat (Anon, 1983).

\section{Sifat Sensoris}

Evaluasi sifat sensoris donat dilakukan dengan uji hedonik terhadap warna, tekstur, aroma, rasa dan penerimaan keseluruhan serta uji skoring terhadap tekstur donat. Nilai rata-rata uji hedonik terhadap warna, tekstur, aroma, rasa dan penerimaan keseluruhan donat dapat dilihat pada Tabel 5 serta nilai rata-rata uji skoring terhadap tekstur dapat dilihat pada pada Tabel 6 . 
Tabel 5. Nilai Rata-Rata Uji Hedonik Warna, Tekstur, Aroma, Rasa dan Penerimaan Keseluruhan Donat.

\begin{tabular}{|c|c|c|c|c|c|}
\hline \multirow{2}{*}{$\begin{array}{c}\text { Terigu : } \\
\text { Pasta } \\
\text { Brokoli }\end{array}$} & \multicolumn{5}{|c|}{ Nilai Rata-Rata Uji Hedonik } \\
\hline & Warna & Aroma & Rasa & Tekstur & $\begin{array}{c}\text { Penerimaan } \\
\text { Keseluruhan }\end{array}$ \\
\hline (P0)100:0 & $4,9 \pm 1,03 \mathrm{a}$ & $5,2 \pm 1,20 \mathrm{ab}$ & $4,7 \pm 1,1 \mathrm{a}$ & $4,7 \pm 1,23 \mathrm{a}$ & $4,7 \pm 1,28 \mathrm{a}$ \\
\hline (P1)90:10 & $5,0 \pm 1,07 \mathrm{a}$ & $4,6 \pm 0,91 b c$ & $5,1 \pm 0,99 \mathrm{a}$ & $4,9 \pm 1,19 a$ & $5,5 \pm 0,99 \mathrm{a}$ \\
\hline (P2)80:20 & $5,4 \pm 0,83 \mathrm{a}$ & $5,4 \pm 0,74 a$ & $5,3 \pm 1,03 \mathrm{a}$ & $5,3 \pm 0,9 \mathrm{a}$ & $5,7 \pm 0,9 \mathrm{a}$ \\
\hline (P3)70:30 & $4,7 \pm 1,28 \mathrm{a}$ & $5,1 \pm 1,16 a b c$ & $4,9 \pm 1,34 \mathrm{a}$ & $5,1 \pm 1.13 \mathrm{a}$ & $5,1 \pm 1,39 \mathrm{a}$ \\
\hline (P4)60:40 & $4,7 \pm 1,28 \mathrm{a}$ & $4,5 \pm 1,06 c$ & $4,7 \pm 1,39 a$ & $5,3 \pm 1,16 a$ & $4,7 \pm 1,28 \mathrm{a}$ \\
\hline
\end{tabular}

Keterangan: Huruf yang sama dibelakang nilai rata-rata pada kolom yang sama menunjukkan perlakuan berbeda tidak nyata $(\mathrm{P}>0,05)$.

Tabel 6. Nilai Rata-Rata Uji Skoring Tekstur Donat.

\begin{tabular}{cc}
\hline Terigu : Pasta Brokoli & Nilai Rata-Rata Uji Skoring \\
\cline { 2 - 2 } (P0)100:0 & $3,9 \pm 1,53 \mathrm{~b}$ \\
(P1)90:10 & $4,2 \pm 0,94 \mathrm{~b}$ \\
(P2)80:20 & $4,6 \pm 0,74 \mathrm{~b}$ \\
(P3)70:30 & $5,5 \pm 1,06 \mathrm{a}$ \\
(P4)60:40 & $6,2 \pm 0,94 \mathrm{a}$ \\
\hline
\end{tabular}

Keterangan: Huruf yang sama dibelakang nilai rata-rata pada kolom yang sama menunjukkan perlakuan berbeda tidak nyata $(\mathrm{P}>0,05)$.

\section{Warna}

Berdasarkan data hasil sidik ragam menunjukkan bahwa perbandingan terigu dan pasta brokoli berpengaruh tidak nyata $(\mathrm{P}>0,05)$ terhadap kesukaan warna donat. Tabel 5 menunjukkan bahwa nilai rata-rata penerimaan panelis terhadap warna donat adalah dengan kriteria agak suka.

\section{Aroma}

Hasil sidik ragam pada menunjukkan bahwa perbandingan terigu dan pasta brokoli pada donat berpengaruh nyata $(\mathrm{P}<0,05)$ terhadap uji hedonik aroma dari donat. Tabel 5 menunjukkan nilai rata-rata uji hedonik aroma donat tertinggi diperoleh pada perbandingan terigu $80 \%$ dan pasta brokoli 20\% (P2) dengan kriteria agak suka serta berbeda tidak nyata dengan P0 dan P3, sedangkan nilai rata-rata terendah diperoleh pada donat dengan perbandingan terigu $60 \%$ dan pasta brokoli $40 \%$ (P4) dengan kriteria biasa serta berbeda tidak nyata dengan P1 dan P3.

\section{Rasa}

Hasil sidik ragam pada menunjukkan bahwa perbandingan terigu dan pasta brokoli berpengaruh tidak nyata $(\mathrm{P}>0,05)$ terhadap tingkat kesukaan hedonik rasa dari donat. Tabel 5 menunjukkan bahwa nilai rata-rata dari uji hedonik rasa donat berkisar antara agak suka sampai dengan suka.

\section{Tekstur}

Hasil sidik ragam pada menunjukkan bahwa perbandingan terigu dengan pasta brokoli berpengaruh tidak nyata $(\mathrm{P}>0,05)$ terhadap uji hedonik tekstur donat dengan kriteria agak suka (Tabel 5).

Hasil sidik ragam pada menunjukkan bahwa perbandingan 
terigu dengan pasta brokoli berpengaruh sangat nyata $(\mathrm{P}<0,01)$ terhadap uji skor tekstur donat. Tabel 6 menunjukkan bahwa nilai rata-rata dari uji skor tekstur donat tertinggi diperoleh pada $\mathrm{P} 4$ (60\% terigu : $40 \%$ pasta brokoli) yaitu 6,20 dengan kriteria tekstur empuk serta berbeda tidak nyata dengan P3, sedangkan nilai rata-rata terendah diperoleh pada perlakuan P0 (100\% terigu : 0\% pasta brokoli) yaitu 3,93 dengan kriteria tekstur biasa serta berbeda tidak nyata dengan P1 $(90 \%$ terigu : $10 \%$ pasta brokoli), dan P2 $(80 \%$ terigu : $20 \%$ pasta brokoli).

\section{Penerimaan Keseluruhan}

Berdasarkan data hasil sidik ragam menunjukkan bahwa perbandingan terigu dan pasta brokoli berpengaruh tidak nyata $(\mathrm{P}>0,05)$ terhadap kesukaan warna donat. Tabel 5 menunjukkan bahwa nilai rata-rata penerimaan panelis terhadap warna donat adalah dengan kriteria agak suka sampai suka.

Penerimaan keseluruhan donat dipengaruhi oleh beberapa faktor seperti warna, aroma, tekstur dan rasa. Nilai rata - rata keseluruhan tersebut menunjukkan bahwa donat yang terbuat dari perbandingan terigu dan pasta brokolidapat diterima dengan cukup baik oleh panelis.

\section{KESIMPULAN DAN SARAN}

\section{Kesimpulan}

Berdasarkan hasil penelitian yang telah dilakukan dapat diambil kesimpulan sebagai berikut:

1. Perbandingan terigu dengan pasta brokoli berpengaruh terhadap kadar air, kadar lemak, kadar serat kasar, kadar vitamin $\mathrm{C}$, kadar klorofil, daya kembang, aroma (hedonik), dan tekstur (skoring) donat.

2. Perbandingan $60 \%$ terigu : $40 \%$ pasta brokoli merupakan perlakuan yang menghasilkan donat dengan karakteristik terbaik dengan kadar air $18,80 \%$, kadar lemak $17,30 \%$, kadar serat kasar 4,92\%, kadar vitamin C 2,93 $\mathrm{mg} / \mathrm{g}$, kadar klorofil 3,97 $\mathrm{mg} / \mathrm{kg}$, daya kembang $27,20 \%$, warna agak suka, aroma biasa, rasa agak suka, tekstur empuk dan agak suka, penerimaan keseluruhan agak suka.

\section{Saran}

Berdasarkan penelitian diatas disarankan dalam proses pembuatan donat menggunakan perbandingan $60 \%$ terigu : $40 \%$ pasta brokoli sehingga menghasilkan donat dengan karakteristik terbaik.

\section{DAFTAR PUSTAKA}

Aminah, Siti., dan Hersoelistyorini, W. 2016. Budidaya Tanaman Brokoli. Makalah. Program Studi Agroekoteknologi Fakultas Pertanian. Universitas Andalas. Dharmasraya

Anonimus. 1981. Pedoman Pembuatan Roti dan Kue. U.S. Wheat Associated Djambatan, Jakarta.

Anonimus. 1983. Tepung Terigu; Cara Memilih Tepung Terigu http://terbaru2010.com/tepungterigu-cara-memilih-tepung-teri gu.html Diakses tanggal: 7/1/2019.

Anonimus. 2000. Standar Nasional Indonesia (SNI) 01-2000. Donat. Dewan Standarisasi Nasional-DSN. Jakarta. 
Gomez, K. A. dan A. A. Gomez. 1995. Prosedur Statistik Untuk Penelitian Pertanian. UI Press. Jakarta.

Junda Y. 2013. Sukses Peluang Usaha Makanan Koki Instan. Diakses tanggal 18 Agustus 2018.

http://www.thekokiinstan.com.

Munawwarah. 2017. Analisis Kandungan Zat Gizi Donat Wortel (Daucus carota L.) Sebagai Alternatif Pervaikan Gizi Pada Masyarakat. skripsi. Makassar (ID): Universitas Islam Alauddin Makassar.

Nollet, LML. 2004. Handbook of Food Analysis. Physical Characterzati-ion and Nutrient Analysis. Marcel Dekker. Inc. 1(2). New York.

Soekarto, S.T. 1985. Penilaian Organoleptik Untuk Industri Pangan dan Pertanian. Bharata Karya Aksara. Jakarta.

Sudarmadji, S. B. Haryono dan Suhardi. 1997. Prosedur Analisa Untuk Bahan Makanan dan Pertanian. Liberty. Yogyakarta.

Vuong, Q.V., S. Hirun, T.L.K. Chuen, C.D. Goldsmith, M.C.
Bowyer, A.C. Chalmers, P.A. Phillips dan C.J. Scarlett. 2014. Physicochemical composition, antioxidant and anti-proliferative capacity of a lilly pilly (Syzygium paniculatum) extract. Herbal Medicine. 4(3): 134-140.

Wasonowati, C. 2009. Kajian saat pemberian pupuk dasar nitrogen dan umur bibit pada tanaman brokoli (Brassica oleracea L. var. italica Plenck.). Jurnal Agrovivor. Volume 2

Yenti, N. 2016. Teknologi Produksi Tanaman Hortikultura "Budidaya Tanaman Brokoli". Makalah. Fakultas Pertanian, Universitas Andalas Dharmasraya.

Zuhrina. (2011). Pengaruh Penambahan Tepung Kulit Pisang Raja Terhadap Daya Terima Kue Donat. Skripsi. Medan: Fakultas Kesehatan Masyarakat, Universitas Sumatera Utara Medan. 